\title{
Diversity and selection of MHC class I genes in the Godlewski's bunting
}

\author{
Wei Huang ${ }^{1}$, Boye Liu ${ }^{1}$, Tobias Lenz ${ }^{2}$, Yangyang Peng ${ }^{1}$, Yan-Yun Zhang ${ }^{3}$, and Lu Dong ${ }^{1}$ \\ ${ }^{1}$ Beijing Normal University \\ ${ }^{2}$ Max Planck Institute for Evolutionary Biology \\ ${ }^{3}$ School of Life Sciences, Beijing Normal University
}

December 14, 2020

\begin{abstract}
The major histocompatibility complex (MHC) is a multiple-copy immune gene family in vertebrates. Its genes are highly variable and code for antigen-presenting molecules. Characterization of MHC genes in different species and investigating the mechanisms that shape MHC diversity is an important goal in understanding the evolution of biological diversity. Here we developed a next generation sequencing (NGS) protocol to genotype the MHC class I genes of 326 Godlewski's buntings (Emberiza godlewskii) sampled in the Western mountain area of Beijing from 2014 to 2016. A total of 184 functional alleles were identified, including both non-classical and classical alleles. Classical alleles could be clustered into nine supertypes. Compared with other passerine birds, the individual diversity of MHC class I genes in Godlewski's buntings is intermediate. Ten amino acid sites in the antigen-binding domain showed signatures of positive selection and eight of them exhibit high amino acid polymorphism. These findings indicate the action of balancing selection and provide a framework for subsequent investigation of selection acting on MHC genes in Godlewski's buntings.
\end{abstract}

\section{Hosted file}

bunting MHC_submission.pdf available at https://authorea.com/users/382859/articles/498727diversity-and-selection-of-mhc-class-i-genes-in-the-godlewski-s-bunting 

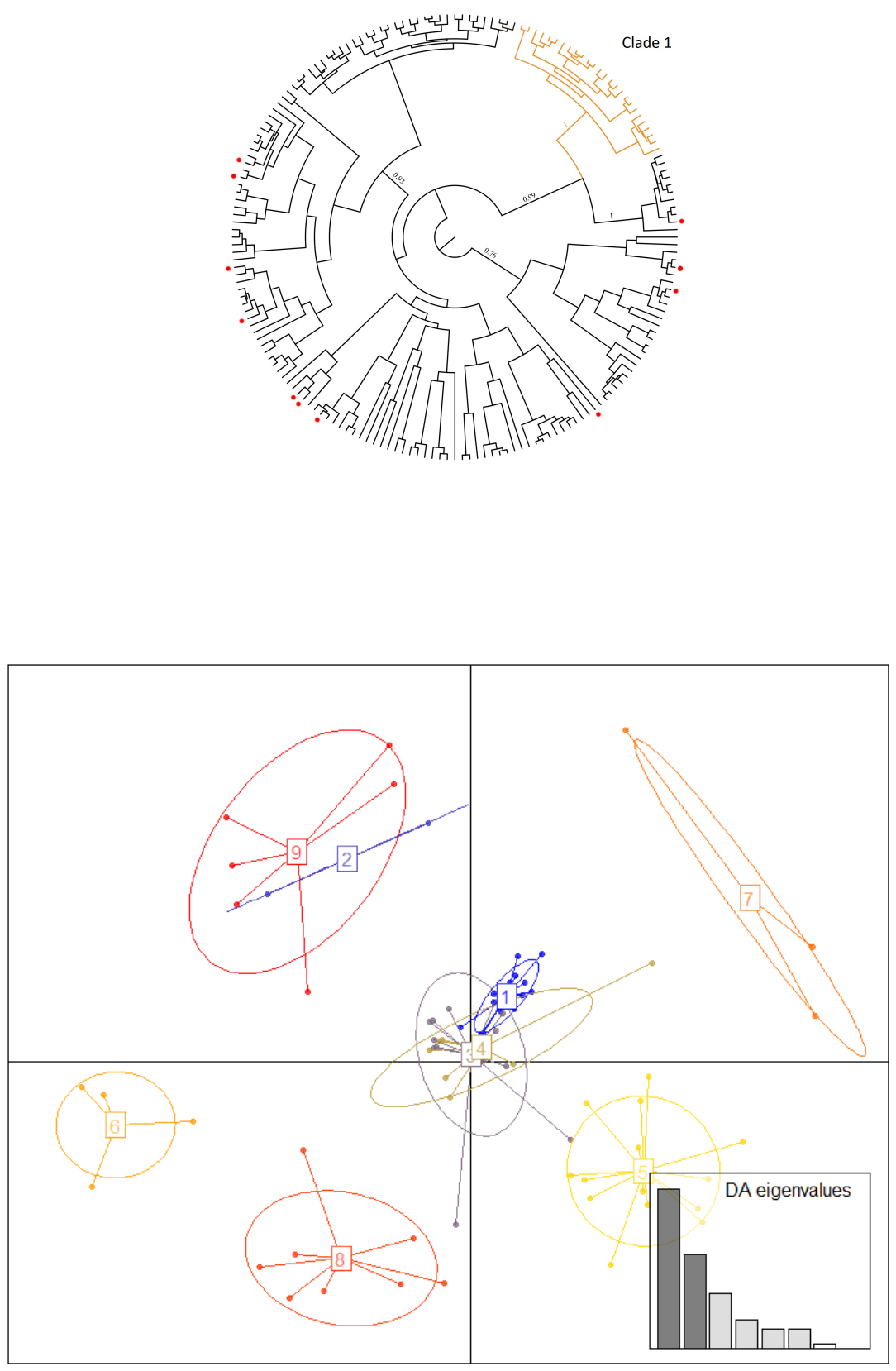


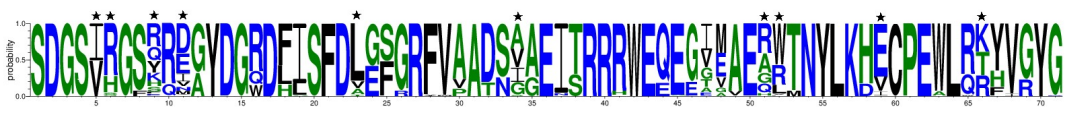

